\title{
Severe Neonatal Hyperbilirubinemia and Kernicterus: Are These Still Problems in the Third Millennium?
}

\author{
Michael Kaplan ${ }^{a, b}$ Ruben Bromiker ${ }^{a, b}$ Cathy Hammerman ${ }^{a, b}$ \\ a Department of Neonatology, Shaare Zedek Medical Center, and ${ }^{\mathrm{b}}$ Faculty of Medicine of the Hebrew University, \\ Jerusalem, Israel
}

\section{Key Words}

Kernicterus - Bilirubin encephalopathy $\cdot$ Bilirubin • Glucose-6-phosphate dehydrogenase deficiency · Late prematurity - ABO blood group heterospecificity · Exchange transfusion - Phototherapy

\begin{abstract}
Despite efforts to eliminate permanent and irreversible brain damage due to bilirubin encephalopathy and kernicterus, these conditions continue to accompany us into the third millennium. This phenomenon occurs not only in developing countries with emerging medical systems, but in Westernized countries as well. Comprehensive guidelines to detect newborns with jaundice and treat those in whom hyperbilirubinemia has already developed have been formulated in several countries, but have not been successful in completely eliminating the problem. In this appraisal of the situation we review selected aspects of bilirubin encephalopathy and/or kernicterus. We highlight recent reports of severe hyperbilirubinemia and kernicterus, discuss some of the factors responsible for the continuing appearance of these conditions, and briefly review what can be done to decrease bilirubin-related morbidity and mortality to the minimum.

Copyright $\odot 2011$ S. Karger AG, Basel
\end{abstract}

Kernicterus is a chronic condition characterized by choreoathetotic cerebral palsy, hearing loss, paralysis of upward gaze and, sometimes, intellectual deficits [1-3]. The term kernicterus, which refers to pathologic staining of the brainstem nuclei (Greek for 'jaundice of the nuclei') was first used by Schmorl [4] and has now entered regular medical usage. Additional terms are sometimes used interchangeably, but in fact, designate different entities. Thus classic 'kernicterus' should typically be used in the context of chronic neurologic disease, while the term 'bilirubin encephalopathy' [acute bilirubin encephalopathy (ABE)] should, in fact, refer to the acute phases of the condition seen in the first days and weeks following the acute hyperbilirubinemic event [5]. The term bilirubin-induced neurologic dysfunction refers to a subtle form of brain injury, also due to the effect of bilirubin toxicity, but comprising less obvious neurodevelopmental disorders or manifestations than seen in classic kernicterus. These may include deafness, disorders of auditory processing and visual motor paralysis $[2,6]$.

Presented at the International Symposium 'Recent Advances in Neonatal Medicine', Würzburg, 2011.

\section{KARGER}

Fax +41613061234 E-Mail karger@karger.ch www.karger.com
Prof. Michael Kaplan

Department of Neonatology, Shaare Zedek Medical Center

PO Box 3235

Jerusalem 91031 (Israel)

Tel.+972 2655 5643, E-Mail kaplan@cc.huji.ac.il 
Much of the clinical material cited in this paper was published after the year 2000, and is thus relevant to current practice. It is not our intention to comprehensively appraise all aspects of kernicterus in this review. Rather, we wish to selectively relate to some aspects of why we continue to see cases of kernicterus, and what we can do to prevent, or minimize, these from occurring.

\section{Did the Pendulum Actually Swing?}

Some authors have referred to a disappearance and then resurgence of kernicterus during the last 2 decades $[7,8]$. Hansen [3] has likened the situation to a recurrence of an unpleasant situation: 'the specter walks again'. Undoubtedly, the advent of exchange transfusion, the subsequent introduction of phototherapy and prophylaxis of a major cause of kernicterus, Rh isoimmunization and its associated hemolysis resulted in a decrease in the number of cases of kernicterus in Westernized countries with advanced medical systems. However, there is some controversy as to whether the condition did, in fact, completely disappear for a while and then reappear. Though for a period there were few publications of cases of kernicterus from industrialized countries, one wonders what happened to the cases of kernicterus currently being seen, the result of conditions that have not been eliminated, including glucose6-phosphate dehydrogenase (G-6-PD) deficiency, direct antiglobulin titer (DAT)-positive ABO isoimmunization and late prematurity. While some cases, especially in the latter group, may have been prevented by longer hospital stays and a more aggressive therapeutic approach, it is difficult to comprehend a disappearance and then reappearance of kernicterus associated with $\mathrm{ABO}$ blood group heterospecificity or the sudden, unpredictable and exponential rises in serum bilirubin associated with G-6-PD deficiency $[9,10]$.

In favor of the resurgence theory, some case reports of kernicterus surfaced in the US after a period of relative 'publication silence' [11-13] and culminated in the publication of the provisional (2004) and subsequently final (2009) report of the Kernicterus Registry [14, 15]. In Denmark, in a search of medical registries, insurance and other records, and in direct approaches to each of the pediatric departments in that country, Ebbesen [16] could find no cases of kernicterus during the 20 years preceding 1994, but did uncover 6 cases between 1994 and 1998 . Subsequently, during 2000-2001, Ebbesen et al. [17] identified 32 near-term and term infants in whom the serum total bilirubin (STB) values exceeded the indications for exchange transfusion, the median value for which was $450 \mu \mathrm{mol} / \mathrm{l}(26.3 \mathrm{mg} / \mathrm{dl})$. Twelve of these infants had signs and symptoms of central nervous system involvement including 11 with evidence of ABE. Many of the infants were readmitted after having been discharged as healthy; readmitted babies frequently had a higher incidence of clinical bilirubin encephalopathy than in those in whom the hyperbilirubinemia developed in hospital. This finding may have been due to higher STB concentrations in combination with prolonged exposure to toxic bilirubin levels. In the US, Burke et al. [18] used data from the Healthcare Cost and Utilization Project Nationwide Inpatient Sample and Kids' Inpatient databases to determine kernicterus time trends. They reported a $70 \%$ decrease in hospitalizations between 1988 and 2005 of neonates with a diagnosis of kernicterus.

On the other hand, Brooks et al. [19], using strict ICD9 codes for kernicterus from the California Department of Developmental Services, identified 25 cases of physician-confirmed strictly diagnosed kernicterus during the 10-year period of 1988-1997, equivalent to an incidence of 0.44 per 100,000 live births in California during this period. The incidence was constant during the study period and was not significantly different between the periods 1988-1993 and 1994-1997. The same authors studied the issue on a national US basis by extracting mortality data due to kernicterus from the Centers for Disease Control and Prevention databases. Thirty-one infant deaths with kernicterus as an underlying cause were reported from 1979 to 2006. The kernicterus death incidence during the first 14 years of the study period was not significantly different from that of the second study time epoch.

Whether there was or was not a disappearance and resurgence of kernicterus is still not clear. What is important is that, in the year 2011, kernicterus is still with us and making a major contribution to neonatal and childhood mortality and morbidity, as will be seen in the following sections.

\section{Kernicterus in the Third Millennium}

\section{Developing Countries}

While undoubtedly a tragedy, it is not surprising that kernicterus continues to occur in developing countries, with as yet underdeveloped health services, or in war zones. Perhaps the most devastating of recent reports emanates from Baghdad, Iraq, where there has been a severe breakdown of medical services [20]. Of 162 infants ad- 
mitted for severe hyperbilirubinemia [STB up to 770 $\mu \mathrm{mol} / \mathrm{l}(45 \mathrm{mg} / \mathrm{dl})], 22 \%$ had advanced ABE, $12 \%$ died within $48 \mathrm{~h}$ of admission and $21 \%$ had posticteric sequelae. Almost all babies were $<10$ days old. Evidence of advanced $A B E$ at the time of admission increased the risk for the adverse outcome of kernicterus or death eightfold. Some other reports from developing countries since the year 2000 derive from Nigeria [115 babies with ABE, of whom $42(36.5 \%)$ died] [21], Oman [14 cases of whom 4 (28.5\%) died] [22] and Turkey [10 G-6-PD-deficient neonates, of whom 5 (50\%) developed kernicterus] [23]. In Kuwait and the United Arab Emirates, newborns with kernicterus were reported following henna applications to their skin [24].

\section{Westernized Countries}

Recent comprehensive reports from Westernized countries emanate from the US [15], Canada [25], the UK and Ireland [26], and Denmark [27]. The US-based Kernicterus Registry provides a record of 125 infants who actually developed kernicterus. The Canadian, UK and Ireland, and Danish studies also included infants with extreme hyperbilirubinemia but without $\mathrm{ABE}$ and, in the case of the Canadian survey, infants who had undergone exchange transfusion. The latter 3 surveys were all performed subsequent to the year 2000. Abnormal neurological signs attributable to bilirubin toxicity were seen in 20,13 and 39\% of the Canadian, UK and Ireland, and Danish groups, respectively. Overall, the most common etiologic entities found were $\mathrm{ABO}$ blood group heterospecificity (not necessarily DAT-positive) and G-6$\mathrm{PD}$ deficiency, both overrepresented relative to their frequency in the respective background population groups. A striking feature is the readmission of many infants who had been discharged as healthy from birth hospitalization. Breastfeeding played a prominent role in those Danish infants in whom no other etiological cause for hyperbilirubinemia could be found. Black ethnicity and minority groups were also overrepresented, relative to the home population, in the US and UK/Ireland groups.

In a survey of 109 level III neonatal units in Italy, 16 cases of kernicterus were reported during the decade preceding 2010 [28]. Eleven of these cases were in term infants, while 5 were found in preterms. Similarly, between 2003 and 2005, a national surveillance system in Germany uncovered 11 cases of kernicterus [29]. Among this group, late prematurity and readmission of previously healthy babies were common.

\section{Clinical Picture of Kernicterus}

\section{Acute Bilirubin Encephalopathy}

Newborns with ABE present a clinical picture very different from the chronic form, as recently reviewed [2]. The features associated with severe hyperbilirubinemia include, in the early stages, lethargy and poor feeding. These signs are nonspecific for bilirubin encephalopathy and if not suspected by the treating physician, may lead to delay in diagnosis and timely institution of therapy. As the disease process progresses, muscle tone may fluctuate between hypo- and hypertonia and a high-pitched cry develops. Later, spasm of the extensor muscles with back arching, opisthotonus, retrocollis and impairment of upward gaze resulting in the 'setting sun sign' appear, while fever, seizures, apnea and death may complete the picture [2]. Sgro et al. [30] recently documented the clinical picture of 32 newborns whose STB ranged from 426-773 $\mu \mathrm{mol} / \mathrm{l}(24.9-45.2 \mathrm{mg} / \mathrm{dl})$ and who had neurological findings at the time of admission. Cardinal clinical features included hypotonia, poor suck, lethargy and abnormal auditory-evoked responses. Opisthotonus, retrocollis, apnea, seizures, irritability and hypertonia were found, but to a lesser extent. Not surprisingly, infants in the highest peak bilirubin level group [ $>550 \mu \mathrm{mol} / 1$ ( 32 $\mathrm{mg} / \mathrm{dl})$ ] who presented within the first 2 days of life or who had exchange transfusion were at higher risk for presenting with signs of bilirubin encephalopathy. The authors suggest that the rapid increase in serum bilirubin in those with early presentation may have potentiated an increased risk of $\mathrm{ABE}$.

\section{Chronic Kernicterus}

The clinical picture of kernicterus in its chronic form has been well described [2]. Affected individuals may display a dystonic or athetoid movement disorder, an auditory processing disturbance which may be associated with hearing loss, motor ocular impairment of upward gaze, enamel dysplasia of the teeth, and hypotonia and ataxia due to cerebellar involvement. The 25 above-mentioned California cases of strict definition kernicterus serve to provide a glum picture of these severely disadvantaged children [19]. Seventy-two percent were male. At a mean (SD) age of 7.8 (3.9) years, $60 \%$ did not walk at all, and only $16 \%$ were able to walk unaided. A feeding tube was in place in $12 \%$, while only $52 \%$ could self-feed orally. Severe or profound mental retardation, or severe disablement precluding testing or completion of testing was found in $36 \%$, while only $32 \%$ had no evidence of mental retardation. Epilepsy was found in $20 \%$. Severe, 
profound or untestable visual impairment was documented in a quarter of the cases. Severe, profound or untestable hearing impairment was a feature affecting $56 \%$ of the group, with only $36 \%$ having normal hearing. Motor spasticity was seen in $32 \%$, ataxia and dyskinesis in $12 \%$ each, and hypotonia in $8 \%$.

\section{Does ABE Necessarily Predict Chronic Disease?}

There is some evidence to suggest that the occurrence of $\mathrm{ABE}$ may not necessarily translate into permanent neurological sequelae. Harris et al. [31] identified 6 exclusively or partially breastfeeding term and near-term infants from 1993 to 1996 who were readmitted to hospital within the first week of life. Five infants had bilirubin values $>513 \mu \mathrm{mol} / \mathrm{l}(30 \mathrm{mg} / \mathrm{dl})$ and abnormal neurologic signs were already present at the time of admission in 5 infants. Three of the 4 infants who had initial MRIs had increased signal intensity in the basal ganglia consistent with kernicterus, while 2 had abnormal auditory-evoked responses. Infants were treated aggressively with phototherapy, intravenous fluids and, in 5 of the 6, exchange transfusions. At follow-up examinations between 3 months and 2 years, the clinical signs had resolved in all but 1 infant. Four infants had a subsequently normal MRI and only 1 had residual hearing impairment.

Hansen et al. [32] recently reported 6 infants from 4 European countries who presented with symptoms and signs commensurate with intermediate-to-advanced acute phase bilirubin encephalopathy. Clinical features included seizures, shrill cry, pronounced muscular hypotonia, apnea, anorexia and opisthotonos/retrocollis. In 2 of the 4 infants who had had an MRI performed, findings typical of kernicterus were found. Subsequently, complete normalization was observed in 4 of the 6 infants. The 5th had hearing loss while the 6th had severe residual neurological sequelae.

Similarly, 3 of 11 surviving newborns with bilirubin encephalopathy in the UK and Ireland survey were found to be normal on follow-up [26].

The virtual absence of long-term neurological deficits attributable to bilirubin disease, except for 1 infant, in the above-mentioned Danish infants who were available for follow-up is also noteworthy [27]. However, it must be recognized that only $28 \%$ of those originally included were available for these follow-up studies.

Severe Neonatal Hyperbilirubinemia and Kernicterus

\section{STB versus Serum Unbound Bilirubin in the Prediction of Kernicterus}

The correlation between increasing STB concentrations and the development of kernicterus in $\mathrm{Rh}$ isoimmunized babies with severe hemolysis was described many years ago [33]. More recently, in the post- $\mathrm{Rh}$ isoimmunization era, it has become clear that the serum total bilirubin value correlates poorly with the subsequent development of kernicterus. There is also no single cutoff point above which an infant will categorically develop bilirubin encephalopathy and/or kernicterus, or below which a baby will remain safe [34-36]. Many factors, including prematurity or the presence of hemolysis, may interact with the total bilirubin to precipitate or prevent the development of kernicterus. The unbound bilirubin fraction, i.e. the fraction which is not bound to serum albumin, has a greater propensity for traversing the bloodbrain barrier and entering the basal nuclei than that which is attached to bilirubin. Thus, the unbound fraction may predict subsequent bilirubin-induced neurologic dysfunction, bilirubin encephalopathy or kernicterus to a greater extent than the total bilirubin value [37]. Unfortunately, unbound bilirubin determination is not available as a clinical tool, and, for practical purposes, we have to rely on the total serum bilirubin both to monitor babies for hyperbilirubinemia and for therapeutic decision-making. Unbound bilirubin values may be used in the future to determine the risk of an individual baby developing kernicterus and to decide on therapeutic procedures. Of practical implication, suggesting the need for cautious evaluation of hyperbilirubinemic neonates who have undergone abdominal surgery, may be the recent finding of hypoalbuminemia associated with increased unbound bilirubin, the latter both individually and relative to total serum bilirubin, in neonates who had undergone abdominal surgery compared with controls in whom surgery had not been performed [38].

\section{Some Specific Conditions with a High Propensity for Kernicterus}

\section{Hemolytic versus Nonhemolytic Conditions}

Neonates with hemolytic disease or a hemolytic process may be at higher risk of developing bilirubin encephalopathy or kernicterus than those without an obvious hemolytic condition, as reviewed [39,40]. Whereas an STB concentration of $342-410 \mu \mathrm{mol} / \mathrm{l}(20-24 \mathrm{mg} / \mathrm{dl})$ may be associated with kernicterus in a neonate with $\mathrm{Rh}$ iso-

Neonatology 2011;100:354-362 
immunization, in the absence of a hemolytic condition, an otherwise healthy term infant will rarely be endangered by TSB concentrations in this range.

Few studies actually offer data supportive of this concept. In a study by Ozmert et al. [41], a positive DAT, used as a presumed marker of hemolysis, was associated with lower IQ scores and a higher incidence of neurologic abnormalities than in controls without a positive test. Similarly, Nilsen et al. [42] found that in DAT-positive Norwegian males who had neonatal hyperbilirubinemia for longer than 5 days, IQ scores were significantly lower than average for the general population. In the Jaundice and Infant Feeding Study, Newman et al. [43] evaluated newborns whose STB was $\geq 428 \mu \mathrm{mol} / \mathrm{l}(25 \mathrm{mg} / \mathrm{dl})$ at the 5 -year follow-up. The subgroup which coexpressed hyperbilirubinemia and positive DAT had significantly lower IQ scores than did hyperbilirubinemic counterparts, but with negative DAT. Kuzniewicz and Newman [44] recently reanalyzed data from the Collaborative Perinatal Project, performed between 1959 and 1966, to evaluate possible interaction between a positive DAT result and bilirubin level on neurodevelopmental outcome. Compared with hyperbilirubinemic [STB $\geq 428 \mu \mathrm{mol} / 1$ $(25 \mathrm{mg} / \mathrm{dl})]$ newborns with a negative DAT result, those infants who were also DAT-positive had significantly lower full-scale IQ scores.

The exact mechanism of the effect of hemolysis in possibly increasing the risk of bilirubin-induced neurologic dysfunction is unknown. One possibility is that hemolyzing babies may have a higher unbound bilirubin fraction than those not actively hemolyzing, but there is no evidence supportive of this concept. Sudden increases in the STB may preclude a 'safety mechanism' whereby bilirubin is distributed within the body's tissues. Resultant high STB concentrations may predispose to bilirubin crossing the blood-brain barrier.

Hemolysis should not be regarded as a prerequisite for developing bilirubin encephalopathy. Babies without obvious hemolysis, but who did develop kernicterus have been reported [12]. The Crigler-Najjar syndrome, associated with hyperbilirubinemia but not with increased hemolysis, may frequently be complicated by bilirubin encephalopathy [45].

\section{Specific Hemolytic Conditions}

Both immune and nonimmune hemolytic conditions contribute to a large extent to series of infants with extreme hyperbilirubinemia or bilirubin encephalopathy $[15,25-27]$. While nowadays $\mathrm{Rh}$ disease is seldom encountered in most Westernized countries, this situation is not necessarily so in developing countries. In India, Pakistan and Nigeria, for example, the majority of women do not receive anti-D prophylaxis and it is estimated that thousands of women will develop anti-RhD antibodies annually [46]. Approximately half the babies born to these women will develop Rh hemolytic disease, and Zippursky and Paul [46] estimate that as many as 100,000 children may be born annually with $\mathrm{RhD}$ hemolytic disease in developing countries.

Currently, the most common etiologic condition resulting in hyperbilirubinemia due to immune hemolysis is DAT-positive ABO heterospecificity. Anti-C, anti-E and other isoimmunizations, while rare, may result in severe hyperbilirubinemia and kernicterus. On the nonimmune front, G-6-PD deficiency continues to play an important part in the pathophysiology of kernicterus, with hereditary spherocytosis and pyruvate kinase deficiency occurring less frequently.

G-6-PD deficiency warrants special mention $[9,10]$. The condition is transmitted via the $\mathrm{X}$ chromosome, and as a result males are more frequently affected than females. Affected newborns develop hyperbilirubinemia to a greater extent than G-6-PD-adequate controls. This hyperbilirubinemia may be attributed to a combination of moderately increased hemolysis in combination with a predilection for diminished bilirubin conjugation [47, $48]$, the latter due to presence of a $(\mathrm{TA})_{7}$ polymorphism (UGT1A1 ${ }^{*} 28$ ) in the promoter of the A1 exon encoding the UDP-glucuronosyltransferase (UGT1A1) bilirubinconjugating enzyme [49]. Occasionally a severe episode of hemolysis may result in large amounts of bilirubin being produced, which may overcome even the most efficient bilirubin-conjugating systems. Exponential increases in the STB may follow with the tragic complication of kernicterus in its wake. As already noted, G-6-PD deficiency is overrepresented, compared with the background population, in series of infants with extreme hyperbilirubinemia or kernicterus [15, 25, 26]. Neonatal screening for G-6-PD deficiency is available [50]. While precautionary measures will not prevent acute hemolytic attacks in all infants, the knowledge that their infant is G-6-PD-deficient should increase parental awareness of the dangers of the condition and facilitate early approach to medical facilities to obtain treatment.

\section{Nonhemolytic Conditions}

Late Preterm Infants

A major nonhemolytic risk factor exacerbating severe neonatal hyperbilirubinemia with the potential for developing kernicterus is that of late preterm gestation (new- 
borns born between 34 and 36 completed weeks) [51, 52]. Activity of the bilirubin-conjugating enzyme UGT 1A1 is more immature than in the term infant and as a result bilirubin conjugation may be diminished. The prevalence, severity and duration of neonatal jaundice in late preterm infants may be exacerbated when coexistent with breastfeeding, male sex, G-6-PD deficiency or other icterogenic factors. While many of these infants are cared for in a regular well-baby nursery, they should be treated with great caution and not as if they were regular babies. In-hospital screening for jaundice, adequate parental education and meticulous postdischarge follow-up are necessary to detect those in the process of developing hyperbilirubinemia so as to institute treatment prior to the serum bilirubin reaching dangerous levels.

\section{Very Low Birth Weight Premature Infants}

Despite the high frequency of some degree of clinical jaundice in very low birth weight (VLBW) newborns, autopsy findings of kernicterus in these infants at low peak concentrations of STB (low bilirubin kernicterus) [53, 54], and the common notion that VLBW premature infants are at high risk for bilirubin-related neurologic damage, bilirubin-attributable neurodevelopmental abnormalities have not consistently been noted in longterm follow-up studies $[55,56]$. Nevertheless, although specific guidelines have yet to be universally agreed to and a wide range of indications exists, management guidelines for the treatment of hyperbilirubinemia in small preterm infants do differ from those for term infants and include commencement of phototherapy and performance of exchange transfusion at lower levels of STB than in term counterparts, as reviewed $[56,57]$.

A dearth of kernicterus, even among cases in whom serum bilirubin levels were allowed to exceed recommended values for performing exchange transfusion, noted in postmortem series of premature infants published in the latter quarter of the last century led some to feel that low bilirubin kernicterus was no longer a major problem in this neonatal group $[58,59]$. However, several reports from diverse countries including Germany [60], Holland [61] and Japan [62-64] comprising at least 10 VLBW infants, all $<28$ weeks' gestation with moderate hyperbilirubinemia in whom the maximal STB concentration did not exceed $272 \mu \mathrm{mol} / \mathrm{l}(15.9 \mathrm{mg} / \mathrm{dl})$ and who developed kernicterus, have recently been published and summarized by Moll et al. [60]. It is of note that neurologic features characteristic of classical ABE were not cardinal features of these infants' clinical courses during the neonatal period. Moll et al. [60] responded to this possi- ble 'resurgence' of low bilirubin kernicterus by lowering the bilirubin thresholds for phototherapy in their nursery for very sick infants with birth weight $<1,000 \mathrm{~g}$ who had additional risk factors including anemia, sepsis or intraventricular hemorrhage. However, because of the inability to relate specific peak STB concentrations to developmental outcome or pathological kernicterus, combined with the rareness of kernicterus in general, it remains to be seen whether this change of strategy will be successful.

A recent study of the NICHD Neonatal Network compared aggressive and conservative phototherapy protocols in tiny premature infants [65]. While aggressive phototherapy in the 751-1,000 g birth weight subset did lead to improved neurodevelopmental and hearing outcomes, disturbingly, there was an increase in mortality in the 500-750 g group who were treated with aggressive phototherapy. While the effect of maximal serum total bilirubin concentration on the development of combinations of death or neurodevelopmental impairment and death or hearing loss in VLBW infants was dependent on the clinical status of the infants, an increasing level of unbound bilirubin was associated with a higher risk of death or adverse neurodevelopmental outcomes regardless of clinical status [66]. Clearly, further study is necessary to determine serum concentrations of STB or unbound bilirubin fractions above which further increases should be prevented.

\section{Kernicterus Is Still with Us: What Can We Do to Prevent It?}

Since the turn of the millennium, several countries have responded to the continuation of appearance of cases of kernicterus by either formulating guidelines for the management of hyperbilirubinemia or modifying preexisting guidelines. The most comprehensive of these, and perhaps the most internationally used, are those of the Subcommittee on Hyperbilirubinemia of the American Academy of Pediatrics published in 2004 with an additional commentary in 2009 [5, 67]. National guidelines have also been published in Canada, the UK, South Africa, Israel and Norway [68-72]. The basic principles of hyperbilirubinemia management include the seeking out and recognition of risk factors with the potential of increasing the development of hyperbilirubinemia or exacerbating bilirubin encephalopathy, vigilant in-hospital and postdischarge clinical monitoring for jaundice, adequate breastfeeding support, and assessment that newborns are being properly hydrated and fed. Indications 
for phototherapy and/or exchange transfusion should be formulated taking into account the dynamic changes in serum bilirubin during the first days of life, risk factors potentiating hyperbilirubinemia and gestational age. Because of early discharge, the peak in serum bilirubin frequently occurs when the infant is already at home, and of paramount importance is the concept that each and every newborn should be assessed for unexpected jaundice by a health authority within a few days of discharge. Any serum or transcutaneous bilirubin value should be plotted on the hour of life specific bilirubin nomogram and assessed along with the risk of subsequent hyperbilirubinemia, according to the percentile for the specific hour of life at which the blood was drawn [73]. More recent recommendations include universal predischarge bilirubin screening of all infants, either by serum sampling or using noninvasive transcutaneous techniques to assess the risk of subsequent hyperbilirubinemia, and planning follow-up [67].

As already noted, neurologic signs attributable to $\mathrm{ABE}$ may be transient provided the infants are treated rapidly and effectively with prompt lowering of the STB. Some newborns may be saved the tragic outcome by early, aggressive and effective treatment. Clinical presence of neurologic signs attributable to hyperbilirubinemia should not be interpreted as a reason to withhold treatment [5]. Extreme hyperbilirubinemia in any newborn should be treated as an acute medical emergency by preparing for exchange transfusion as soon as possible while providing intense phototherapy in the interim in a hospi- tal with facilities for performing exchange transfusion if necessary. The infants should be treated by a 'crash-cart' approach [74].

\section{Conclusions}

Despite major efforts to increase awareness of the condition and formulate guidelines for prevention and treatment, severe neonatal hyperbilirubinemia with the devastating potential, albeit rare, of bilirubin encephalopathy and/or kernicterus continues to plague us into the third millennium. Many cases may be preventable, but because of some conditions associated with sudden, unpredictable and extreme hemolytic crises, it is unlikely that kernicterus will ever be completely eliminated. Abiding by formal guidelines for the detection and treatment of severe hyperbilirubinemia and relating to extreme hyperbilirubinemia as an acute medical emergency will hopefully decrease the incidence of the condition. In developing countries, large sums of money will have to be invested in order to revamp existing medical services and focus on the needs of newborn babies [75].

\section{Disclosure Statement}

The authors have no conflicts of interest to declare with regard to any of the material included in the manuscript.

\section{References}

1 Maisels MJ: Neonatal hyperbilirubinemia and kernicterus - not gone but sometimes forgotten. Early Hum Dev 2009;85:727-732.

2 Shapiro SM: Hyperbilirubinemia and the risk for brain injury; in Perlman J, Polin RA (eds): Neurology: Neonatology Questions and Controversies. Philadelphia, Saunders Elsevier, 2008, pp 195-209.

-3 Hansen TW: Kernicterus in term and nearterm infants - the specter walks again. Acta Paediatr 2000;89:1155-1157.

4 Schmorl CG: Zur Kenntnis des Ikterus neonatorum, insbesondere der dabei auftretenden Gehirnveränderungen. Verh Dtsch Pathol Ges 1904;6:109-115.

$\checkmark 5$ American Academy of Pediatrics Subcommittee on Hyperbilirubinemia: Management of hyperbilirubinemia in the newborn infant 35 or more weeks of gestation. Pediatrics 2004;114:297-316.
6 Shapiro SM: Bilirubin toxicity in the developing nervous system. Pediatr Neurol 2003; 29:410-421.

7 Johnson L, Bhutani VK: Guidelines for man agement of the jaundiced term and nearterm infant. Clin Perinatol 1998;25:555-574.

8 Davidson L, Thilo EH: How to make kernic terus a 'never event'. NeoReviews 2003;4: e308-e314.

$\checkmark 9$ Beutler E: G6PD deficiency. Blood 1994;84: 3613-3636.

-10 Kaplan M, Hammerman C: Glucose-6-phosphate dehydrogenase deficiency and severe neonatal hyperbilirubinemia: a complexity of interactions between genes and environment. Semin Fetal Neonatal Med 2010;15: 1448-1456.

11 MacDonald MG: Hidden risks: early discharge and bilirubin toxicity due to glucose 6-phosphate dehydrogenase deficiency. Pediatrics 1995;96:734-738.
12 Maisels MJ, Newman TB: Kernicterus in otherwise healthy, breast-fed term newborns. Pediatrics 1995;96:730-733.

13 Penn AA, Enzmann DR, Hahn JS, Stevenson DK: Kernicterus in a full term infant. Pediatrics 1994;93:1003-1006.

14 Bhutani VK, Johnson LH, Jeffrey Maisels M, Newman TB, Phibbs C, Stark AR, YearginAllsopp M: Kernicterus: epidemiological strategies for its prevention through systems-based approaches. J Perinatol 2004;24: 650-662.

15 Johnson L, Bhutani VK, Karp K, Sivieri EM, Shapiro SM: Clinical report from the pilot USA Kernicterus Registry (1992 to 2004). J Perinatol 2009;29(suppl 1):S25-S45.

$\checkmark 16$ Ebbesen F: Recurrence of kernicterus in term and near-term infants in Denmark. Acta Paediatr 2000;89:1213-1217. 
-17 Ebbesen F, Andersson C, Verder H, Grytter C, Pedersen-Bjergaard L, Petersen JR, Schaarup J: Extreme hyperbilirubinaemia in term and near-term infants in Denmark. Acta Paediatr 2005;94:59-64.

- 18 Burke BL, Robbins JM, Bird TM, Hobbs CA, Nesmith C, Tilford JM: Trends in hospitalizations for neonatal jaundice and kernicterus in the United States, 1988-2005. Pediatrics 2009; 123:524-532.

-19 Brooks JC, Fisher-Owens SA, Wu YW, Strauss DJ, Newman TB: Evidence suggests there was not a 'resurgence' of kernicterus in the 1990s. Pediatrics 2011;127:672-679.

20 Hameed NN, Na’ Ma AM, Vilms R, Bhutani VK: Severe neonatal hyperbilirubinemia and adverse short-term consequences in Baghdad, Iraq. Neonatology 2011;100:57-63.

-21 Owa JA, Ogunlesi TA: Why we are still doing so many exchange blood transfusion for neonatal jaundice in Nigeria? World J Pediatr 2009;5:51-55.

-22 Nair PA, Al Khusaiby SM: Kernicterus and G6PD deficiency - a case series from Oman. J Trop Pediatr 2003;49:74-77.

$\checkmark 23$ Katar S: Glucose-6-phosphate dehydrogenase deficiency and kernicterus of SouthEast Anatolia. J Pediatr Hematol Oncol 2007; 29:284-286.

-24 Raupp P, Hassan JA, Varughese M, Kristiansson B: Henna causes life threatening haemolysis in glucose-6-phosphate dehydrogenase deficiency. Arch Dis Child 2001; 85:411-412.

25 Sgro M, Campbell D, Shah V: Incidence and causes of severe neonatal hyperbilirubinemia in Canada. CMAJ 2006;175:587-590.

-26 Manning D, Todd P, Maxwell M, Jane Platt M: Prospective surveillance study of severe hyperbilirubinaemia in the newborn in the UK and Ireland. Arch Dis Child Fetal Neonatal Ed 2007;92:F342-F346.

-27 Bjerre JV, Petersen JR, Ebbesen F: Surveillance of extreme hyperbilirubinaemia in Denmark. A method to identify the newborn infants. Acta Paediatr 2008;97:1030-1034.

-28 Dani C, Poggi C, Barp J, Romagnoli C, Buonocore G: Current Italian practices regarding the management of hyperbilirubinaemia in preterm infants. Acta Paediatr 2011;100:666-669.

29 Bartmann P, Schaaff F: Kernicterus in Germany 2003-2005. Pediatric Academic Societies. E-PAS 2007;617936.24.

>30 Sgro M, Campbell D, Barozzino T, Shah V: Acute neurological findings in a national cohort of neonates with severe neonatal hyperbilirubinemia. J Perinatol 2011;31:392-396.

> 31 Harris MC, Bernbaum JC, Polin JR, Zimmerman R, Polin RA: Developmental followup of breastfed term and near-term infants with marked hyperbilirubinemia. Pediatrics 2001;107:1075-1080.
32 Hansen TW, Nietsch L, Norman E, Bjerre JV, Hascoet JM, Mreihil K, Ebbesen F: Reversibility of acute intermediate phase bilirubin encephalopathy. Acta Paediatr 2009;98: 1689-1694.

33 Hsia DY, Allen FH Jr, Gellis SS, Diamond LK: Erythroblastosis fetalis. VIII. Studies of serum bilirubin in relation to kernicterus. $\mathrm{N}$ Engl J Med 1952;247:668-671.

34 Wennberg RP, Ahlfors CE, Bhutani VK, Johnson LH, Shapiro SM: Toward understanding kernicterus: a challenge to improve the management of jaundiced newborns. Pediatrics 2006;117:474-485.

35 Oh W, Stevenson DK, Tyson JE, Morris BH, Ahlfors CE, Bender GJ, Wong RJ, Perritt R, Vohr BR, Van Meurs KP, Vreman HJ, Das A Phelps DL, O'Shea TM, Higgins RD, NICHD Neonatal Research Network Bethesda MD: Influence of clinical status on the association between plasma total and unbound bilirubin and death or adverse neurodevelopmental outcomes in extremely low birth weight infants. Acta Paediatr 2010;99:673-678.

$>36$ Ahlfors CE, Wennberg RP, Ostrow JD, Tiribelli C: Unbound (free) bilirubin: improving the paradigm for evaluating neonatal jaundice. Clin Chem 2009;55:1288-1299.

37 Ahlfors CE: Predicting bilirubin neurotoxicity in jaundiced newborns. Curr Opin Pediatr 2010;22:129-133.

38 Miwa A, Morioka I, Hisamatsu C, Fujioka K, Morikawa S, Shibata A, Yasufuku M, Yokoyama N, Matsuo M: Hypoalbuminemia following abdominal surgery leads to high serum unbound bilirubin concentrations in newborns soon after birth. Neonatology 2011;99:202-207.

39 Newman TB, Maisels MJ: Does hyperbilirubinemia damage the brain of healthy fullterm infants? Clin Perinatol 1990;17:331 358.

40 Watchko JF, Oski FA: Bilirubin $20 \mathrm{mg} / \mathrm{dl}=$ vigintiphobia. Pediatrics 1983;71:660-663.

41 Ozmert E, Erdem G, Topçu M, Yurdakök M, Tekinalp G, Genç D, Renda Y: Long-term follow-up of indirect hyperbilirubinemia in full-term Turkish infants. Acta Paediatr 1996;85:1440-1444.

42 Nilsen ST, Finne PH, Bergsjø P, Stamnes O: Males with neonatal hyperbilirubinemia examined at 18 years of age. Acta Paediatr Scand 1984;73:176-180.

-43 Newman TB, Liljestrand P, Jeremy RJ, Ferriero DM, Wu YW, Hudes ES, Escobar GJ, Jaundice and Infant Feeding Study Team: Outcomes among newborns with total serum bilirubin levels of $25 \mathrm{mg}$ per deciliter or more. N Engl J Med 2006;354:1889-1900.

44 Kuzniewicz M, Newman TB: Interaction of hemolysis and hyperbilirubinemia on neurodevelopmental outcomes in the collaborative perinatal project. Pediatrics 2009;123: 1045-1050.

45 Jansen PL: Diagnosis and management of Crigler-Najjar syndrome. Eur J Pediatr 1999; 158(suppl 2):S89-S94.
46 Zipursky A, Paul VK: The global burden of Rh disease. Arch Dis Child Fetal Neonatal Ed 2011;96:F84-F85.

47 Kaplan M, Rubaltelli FF, Hammerman C, Vilei MT, Leiter C, Abramov A, Muraca M: Conjugated bilirubin in neonates with glucose-6-phosphate dehydrogenase deficiency. J Pediatr 1996;128:695-697.

-48 Kaplan M, Muraca M, Hammerman C, Vilei MT, Leiter C, Rudensky B, Rubaltelli FF: Bilirubin conjugation, reflected by conjugated bilirubin fractions, in glucose-6-phosphate dehydrogenase-deficient neonates: a determining factor in the pathogenesis of hyperbilirubinemia. Pediatrics 1998;102:E37.

-49 Kaplan M, Renbaum P, Levy-Lahad E, Hammerman C, Lahad A, Beutler E: Gilbert syndrome and glucose-6-phosphate dehydrogenase deficiency: a dose-dependent genetic interaction crucial to neonatal hyperbilirubinemia. Proc Natl Acad Sci USA 1997;94: 12128-12132.

50 Kaplan M, Hammerman C: Neonatal screening for glucose-6-phosphate dehydrogenase deficiency: biochemical versus genetic technologies. Semin Perinatol 2011;35:155-161.

51 Watchko JF: Hyperbilirubinemia and bilirubin toxicity in the late preterm infant. Clin Perinatol 2006;33:839-852.

52 Bhutani VK, Johnson L: Kernicterus in late preterm infants cared for as term healthy infants. Semin Perinatol 2006;30:89-97.

53 Harris RC, Lucey JF, Maclean JR: Kernicterus in premature infants associated with low concentrations of bilirubin in the plasma. Pediatrics 1958;21:875-884

54 Gartner LM, Snyder RN, Chabon RS, Bernstein J: Kernicterus: high incidence in premature infants with low serum bilirubin concentrations. Pediatrics 1970;45:906-917.

55 Cashore WJ: Bilirubin and jaundice in the micropremie. Clin Perinatol 2000;27:171179.

56 Maisels MJ, Watchko JF: Treatment of jaundice in low birthweight infants. Arch Dis Child Fetal Neonatal Ed 2003;88:F459-F463.

57 Kaplan M, Eidelman AI: Post factum imposition of exchange transfusion criteria: in defence of neonatologists. Acta Paediatr 2011; 100:479-481.

58 Pearlman MA, Gartner LM, Lee K, Morecki R, Horoupian DS: Absence of kernicterus in low-birth weight infants from 1971 through 1976: comparison with findings in 1966 and 1967. Pediatrics 1978;62:460-464.

59 Watchko JF, Claassen D: Kernicterus in premature infants: current prevalence and relationship to NICHD Phototherapy Study exchange criteria. Pediatrics 1994;93:996-999.

60 Moll M, Goelz R, Naegele T, Wilke M, Poets CF: Are recommended phototherapy thresholds safe enough for extremely low birth weight (ELBW) infants? A report on 2 ELBW infants with kernicterus despite only moderate hyperbilirubinemia. Neonatology 2011; 99:90-94. 
61 Govaert P, Lequin M, Swarte R, Robben S, De Coo R, Weisglas-Kuperus N, De Rijke Y, Sinaasappel M, Barkovich J: Changes in globus pallidus with (pre)term kernicterus. Pediatrics 2003; 112:1256-1263.

-62 Okumura A, Hayakawa F, Kato T, Itomi K, Mimura S, Watanabe K: Preterm infants with athetoid cerebral palsy: kernicterus? Arch Dis Child Fetal Neonatal Ed 2001; 84:F136-F137.

63 Okumura A, Hayakawa F, Maruyama K, Kubota T, Kato K, Watanabe K: Single photon emission computed tomography and serial MRI in preterm infants with kernicterus. Brain Dev 2006;28:348-352.

-64 Okumura A, Kidokoro H, Shoji H, Nakazawa T, Mimaki M, Fujii K, Oba H, Shimizu T: Kernicterus in preterm infants. Pediatrics 2009; 123:e1052-e1058.

-65 Morris BH, Oh W, Tyson JE, Stevenson DK, Phelps DL, O'Shea TM, McDavid GE, Perritt RL, Van Meurs KP, Vohr BR, Grisby C, Yao Q, Pedroza C, Das A, Poole WK, Carlo WA, Duara S, Laptook AR, Salhab WA, Shankaran S, Poindexter BB, Fanaroff AA, Walsh MC, Rasmussen MR, Stoll BJ, Cotten CM, Donovan EF, Ehrenkranz RA, Guillet R, Higgins RD, NICHD Neonatal Research Network: Aggressive versus conservative phototherapy for infants with extremely low birth weight. N Engl J Med 2008;359:18851896.
66 Oh W, Stevenson DK, Tyson JE, Morris BH, Ahlfors CE, Bender GJ, Wong RJ, Perritt R, Vohr BR, Van Meurs KP, Vreman HJ, Das A, Phelps DL, O'Shea TM, Higgins RD, NICHD Neonatal Research Network Bethesda MD: Influence of clinical status on the association between plasma total and unbound bilirubin and death or adverse neurodevelopmental outcomes in extremely low birth weight infants. Acta Paediatr 2010;99:673-678.

67 Maisels MJ, Bhutani VK, Bogen D, Newman TB, Stark AR, Watchko JF: Hyperbilirubinemia in the newborn infant $>$ or $=35$ weeks gestation: an update with clarifications. Pediatrics 2009;124:1193-1198.

68 Guidelines for detection, management and prevention of hyperbilirubinemia in term and late preterm newborn infants (35 or more weeks' gestation) - summary: Paediatr Child Health 2007;12:401-418.

69 National Institute for Health and Clinical Excellence: Neonatal jaundice (clinical guideline 98). 2010. www.nice.org.uk/CG98.
70 Horn AR, Kirsten GF, Kroon SM, Henning PA, Möller G, Pieper C, Adhikari M, Cooper P, Hoek B, Delport S, Nazo M, Mawela B: Phototherapy and exchange transfusion for neonatal hyperbilirubinaemia: neonatal academic hospitals' consensus guidelines for South African hospitals and primary care facilities. S Afr Med J 2006;96:819-824.

71 Kaplan M, Merlob P, Regev R: Israel guidelines for the management of neonatal hyperbilirubinemia and prevention of kernicterus. J Perinatol 2008;28:389-397.

72 Bratlid D, Nakstad B, Hansen TW: National guidelines for treatment of jaundice in the newborn. Acta Paediatr 2011;100:499-505.

73 Bhutani VK, Johnson L, Sivieri EM: Predictive ability of a predischarge hour-specific serum bilirubin for subsequent significant hyperbilirubinemia in healthy term and near-term newborns. Pediatrics 1999;103: 6-14.

74 Hansen TW: The role of phototherapy in the crash-cart approach to extreme neonatal jaundice. Semin Perinatol 2011;35:171-174.

>75 Slusher TM, Zipursky A, Bhutani VK: A global need for affordable neonatal jaundice technologies. Semin Perinatol 2011;35:185191. 